\title{
DESENVOLVIMENTO DE REVESTIMENTOS POR ASPERSÃO TÉRMICA*
}

Renan de Matos Silva ${ }^{1}$

\section{Resumo}

Em função da necessidade constante da redução de custos e aumento da vida útil de equipamentos do setor industrial (como siderurgia, Mineração, entre outros), Aumenta-se a procura por soluções técnicas para tais necessidades. Uma excelente alternativa é fornecer aos equipamentos proteções superficiais que garantem resistência aos mecanismos de desgastes. As perdas econômicas geradas por desgastes prematuros são críticas e generalizados. Estes custos não são somente correlacionados a reposição de novas peças, mas também, paradas de máquinas, perdas de produção, de competitividade e de oportunidade de negócios. Visando melhor atender às necessidades dos clientes e potencializar a performance dos equipamentos, a SMS Group vem desenvolvendo e empregando novas tecnologias de revestimentos por aspersão térmica, com estudos criteriosos apresentando soluções práticas e viáveis.

Palavras-chave: Aspersão Térmica; HVOF; Arco Elétrico; Desgaste

\section{DEVELOPMENT OF THERMAL SPRAY COATINGS}

\begin{abstract}
Due to the constant necessity to reduce costs and increase the useful life of equipment in the industrial sector (Such as Steel industry, mining, and others), the demand for technical solutions to these necessity are increased. An excellent alternative is providing surface protection to the equipment, which increase to it mechanic wear resistance. The economy losses which are results by premature wear are critical and generalized. These costs are not only correlated to new parts replacement, but also, machine downtime, loss of production, competitiveness and business opportunity. Looking forward to better meeting the customer necessities and potentiating equipment, SMS Group has been developing and using new coating technologies by thermal spray, with judicious study providing viable and practical solutions.
\end{abstract}

Keywords: Thermal Spray, HVOF, Arc Spray, Wear.

1 Engenharia Mecânica, Técnico em Automação industrial Mecânica / Estudante de Engenharia Mecânica, Assistente técnico, Coordenação técnica e Vendas, SMS Group, Belo Horizonte, Minas Gerais, Brasil. 


\section{INTRODUÇÃO}

Segundo a AWS - American Welding Society: "Aspersão térmica é um grupo de processos onde materiais metálicos ou não metálicos, finamente divididos, são aspergidos em uma condição fundida ou semi-fundida sobre um substrato preparado, formando assim, um depósito aspergido". [1]

\section{Processo de Aspersão Térmica}
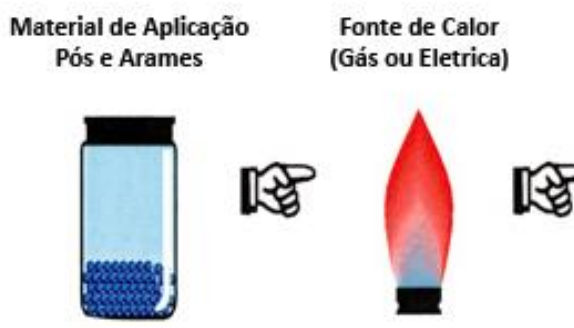
Particulas Fundidas aceleradas

Partículas impactam na peça de trabalho

Revestimento Finalizado
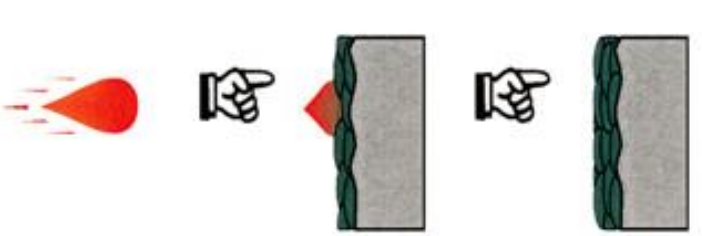

Fonte: ITSA

Figura 1. Processo de Aspersão Térmica.

Tais revestimentos garantem ao substrato novas características, conferindo assim proteção de natureza química (corrosão), mecânica (desgaste) e física (condutividade elétrica, isolamento elétrico, isolamento térmico) além de proporcionar quando necessário, auto lubrificação, redução de atrito e possibilidade de recuperação dimensional. $\mathrm{Na}$ aspersão térmica, os materiais sólidos são aquecidos à uma temperatura extremamente elevada na câmara de combustão da pistola apropriada mudando seu estado para pastoso ou fundido. E logo após a fusão, as partículas em fase de solidificação são aceleradas por gases comprimidos em direção ao substrato (metal-base) que será revestido. As colisões contra a superfície do substrato fazem com que as partículas aspergidas aderem ao substrato por mecanismos de natureza mecânica e em alguns casos de natureza metalúrgica. Estas camadas são constituídas por pequenas partículas deformadas em forma de panquecas em direção paralela ao substrato formando assim uma característica de estrutura lamelar.[2]

De acordo com estas definições, pode-se afirmar que qualquer material que não se decomponha quando fundido pode ser utilizado como revestimento.

Os processos de aspersão térmica podem ser classificados em três grupos, tais estes separados das seguintes formas: Os que utilizam o processo por chama, os que utilizam a energia elétrica e outro que caracterizado como aspersão à frio que utiliza como fonte de energia o mecanismo cinético. Tais processos são divididos e representados como segue na figura abaixo. [3] 


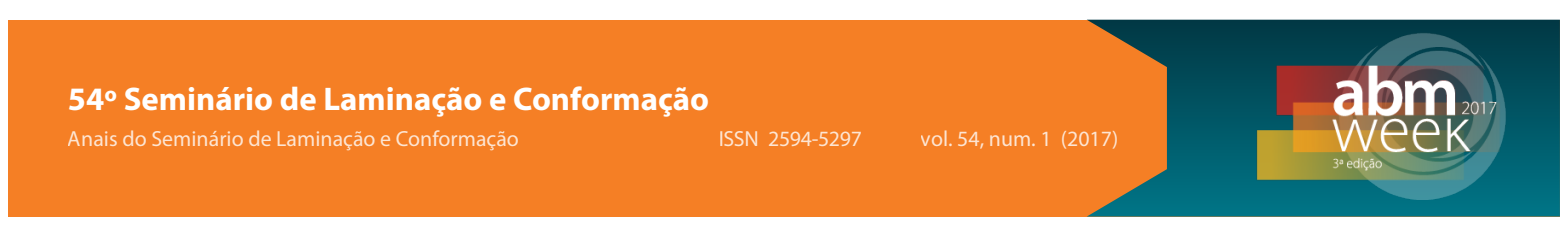

\section{Thermal Spray Processes}

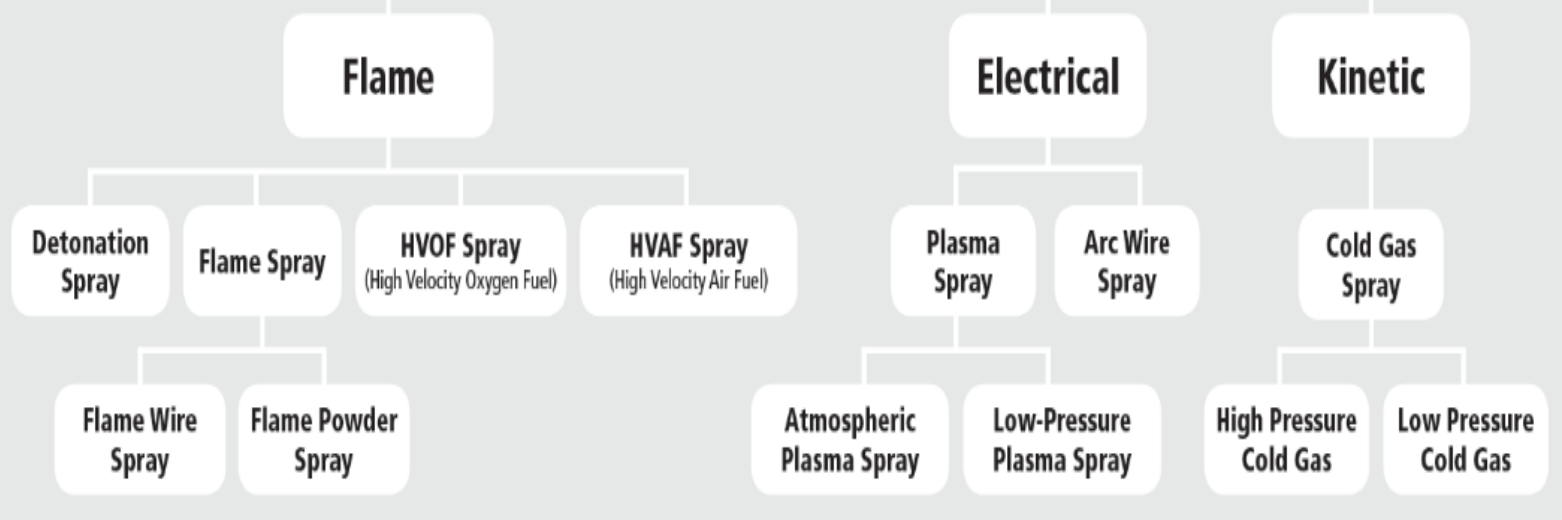

Figura 2. Processos de Aspersão Térmica.

Os processos de aspersão térmica apresentam grande versatilidade na deposição de revestimentos aplicados para a proteção de componentes contra desgaste abrasivo, adesivo, erosivo, corrosão e recuperação dimensional, além de funcionarem, quando necessário, como barreira térmica. A vantagem dessa técnica está relacionada com a versatilidade de revestimentos e a baixa temperatura em que ocorre o processo. Podendo ser aplicado nos mais variados tipos de substrato

Através dos sólidos conhecimentos dos equipamentos mecânicos empregados na Siderurgia e domínio dos processos de revestimentos, nos da SMS Group proporcionamos as melhores soluções adequadas ao cliente, utilizando nossas tecnologias para o desenvolvimento de revestimentos que garantem uma maior vida útil de equipamentos submetidos a variados mecanismos de desgaste. Este documento irá representar estudos de casos e aplicações já realizadas pela SMS Group.

\section{MATERIAIS E MÉTODOS}

Este documento foi desenvolvido considerando as fabricações, reparos e desenvolvimento de revestimentos realizados recentemente e também levando em consideração o desempenho de Placas de Cobre, Rolos e Mancais de Apoio nas principais usinas brasileiras.

\section{RESULTADOS E DISCUSSÃO}

\subsection{Revestimentos UniGuard ${ }^{\mathrm{TM}}$ aspergidos por HVOF em Placas de Cobre}

Seguem abaixo exemplos de resultados de desempenho de placas revestidas com a inclusão do processo de aspersão térmica. 


\subsubsection{ArcelorMittal Cleveland - Aplicação via HVOF de UniGuard ${ }^{\mathrm{TM}}$}

Os primeiros testes na usina ISG Cleveland, nos Estados Unidos, aconteceram em meados de 2002 com foco em aumento da vida útil das placas de cobre estreitas. $O$ revestimento de níquel possuía configuração "full face tapered" e apresentava desgaste excessivo após 100.000 - 125.000 toneladas lingotadas com necessidade de serem substituídas em comparação com as placas largas numa relação de 2:1. As placas largas possuíam um desgaste bastante acentuado se tornando uma preocupação após 150.000-170.000 toneladas. Foi desenvolvido uma configuração de revestimento UniGuard ${ }^{\mathrm{TM}}$ aplicados via HVOF mantendo as mesmas características de extração de calor atingidas pelo revestimento convencional de níquel. Os primeiros testes apresentaram excelentes resultados dobrando a vida em relação ao revestimento convencional de níquel, com campanhas excedendo 300.000 toneladas lingotadas. Em 2004 algumas mudanças adicionais na configuração do revestimento foram realizadas para prolongar a vida do molde atingindo valores acima de 500.000 toneladas. Em 2005 foram retirados de operação três moldes que ultrapassaram uma vida de 500.000 toneladas.

Moldes não são removidos mais por desgaste das placas de cobre, mas por "corner gaps" ou necessidade de manutenção elétrica ou mecânica. Em 2006 foi retirado um molde de operação que atingiu um recorde de 586.913 toneladas lingotadas. A redução de custos associado com a extensão da campanha do molde foram notáveis. Estimativas conservadoras tem mostrado redução no custo de manutenção de moldes pela metade na MLC\#01 da ArcelorMlttal Cleveland.

O desgaste nas placas largas com revestimento UniGuard ${ }^{\mathrm{TM}}$ após 300.000 400.000 toneladas apresentam normalmente um desgaste inferior a $0,25 \mathrm{~mm}$. A significativa redução de desgaste nas placas largas retarda o aparecimento de "corner gaps" e mantém a geometria do molde após campanhas bastante extensas. As Figuras 4 a 7 mostram fotos comparativas dos revestimentos convencionais de Níquel e UniGuard ${ }^{\mathrm{TM}}$ com seus respectivos aspectos de desgaste.

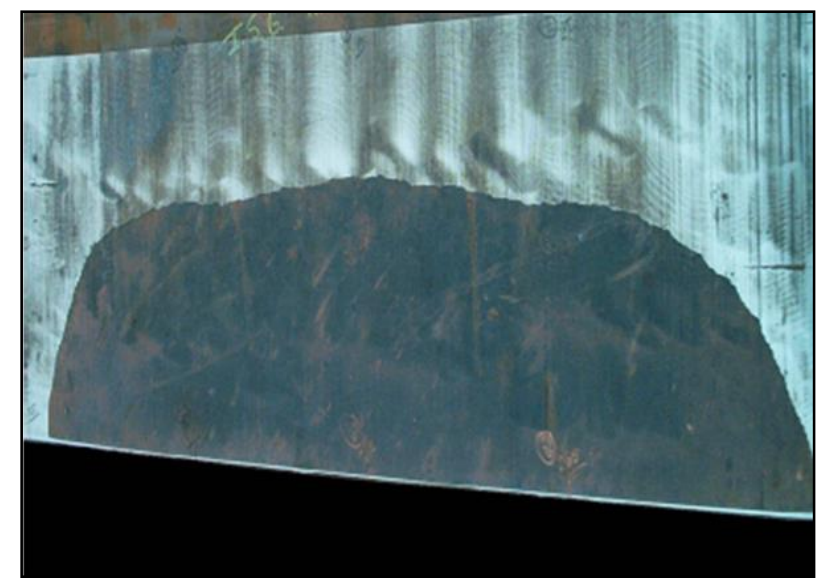

Figura 3. Placa Larga com revestimento de $\mathrm{Ni}$ após 150.000 toneladas. 


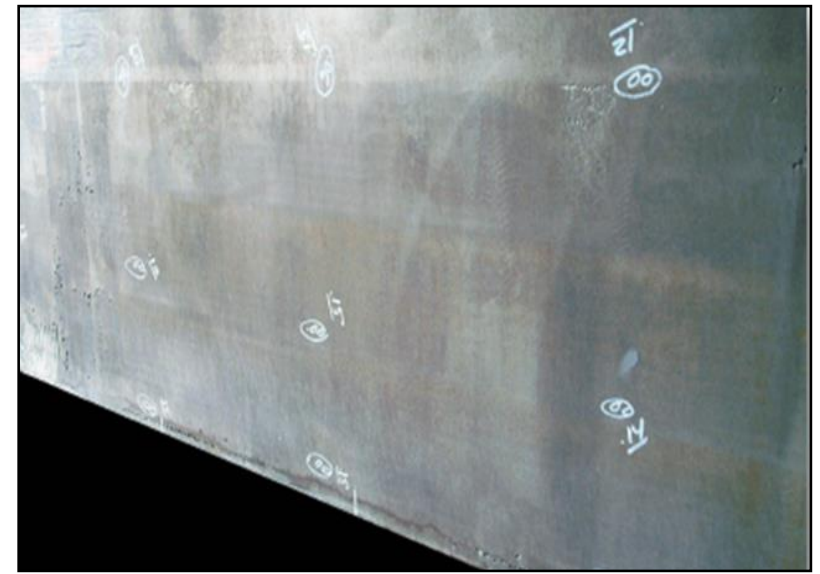

Figura 4. Placa Larga com revestimento UniGuard ${ }^{\mathrm{TM}}$ após 389.000 tonelada

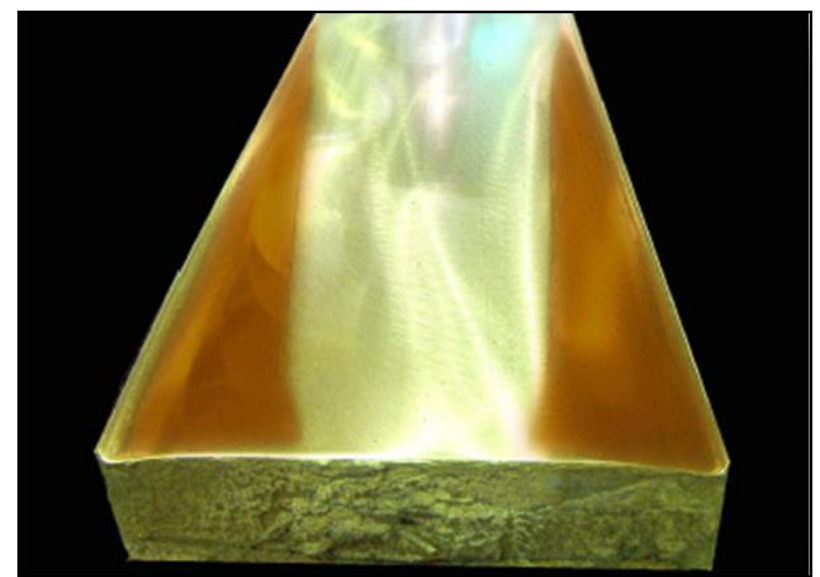

Figura 5. Placa estreita com revestimento de Ni após 125.000 toneladas e desgaste de 3,0 $\mathrm{mm}$.

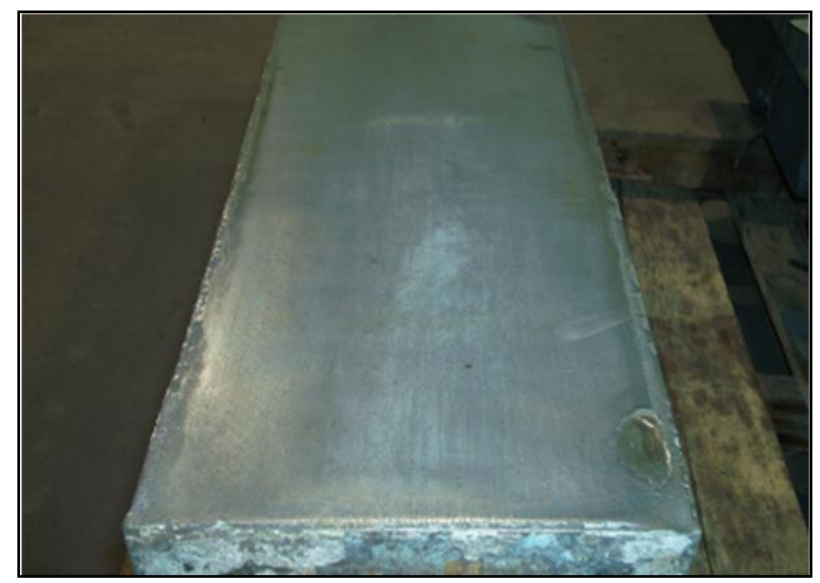

Figura 6. Placa Larga com revestimento UniGuard ${ }^{\mathrm{TM}}$ após 500.000 toneladas e desgaste de $0,25 \mathrm{~mm}$.

Uma vantagem adicional como resultado do aumento da campanha dos moldes, é o aumento da disponibilidade de sobressalentes e redução de aquisição de novas placas de cobre devido à diminuição de desgaste acarretando menor remoção de cobre durante recuperações. A redução de custos com aumento do número de campanhas dos moldes tem sido suficiente para justificar a utilização do revestimento UniGuard ${ }^{\top M}$. A Figura 8 mostra a remoção média de cobre das placas estreitas durante a recuperação com revestimento UniGuard ${ }^{\mathrm{TM}}$ e observa-se metade de redução em comparação com revestimento convencional de níquel. 


\subsubsection{Testes com Revestimento UniGuard ${ }^{\mathrm{TM}}$ no Brasil}

A SMS Siemag tem ofertado o revestimento UniGuard ${ }^{\mathrm{TM}}$ para o mercado brasileiro e alguns testes estão em andamento. A SMS encontrou certa resistência no início dos projetos e foi necessário apresentação de estudo de elementos finitos para provar que a implantação do revestimento não iria trazer danos ao processo e que grandes mudanças não seriam necessárias. A grande dúvida seria como seria 0 comportamento térmico na região do menisco, uma vez que o perfil do revestimento UniGuard" $^{\mathrm{TM}}$ é "full face". A SMS Siemag realizou um estudo para um cliente específico no Brasil para mostrar que a alteração de temperatura na região do menisco seria de aproximadamente $40^{\circ} \mathrm{C}$ e que isso não proporcionaria nenhum dano ao processo. A utilização deste revestimento proporciona uma extração de calor mais suave e esse aumento de temperatura na região do menisco é benéfico ao processo. As Figuras 11 e 12 ilustram os resultados obtidos pela simulação térmica utilizando análise de elementos finitos comparando o revestimento convencional step níquel com revestimento UniGuard ${ }^{\mathrm{TM}}$ "full face" .

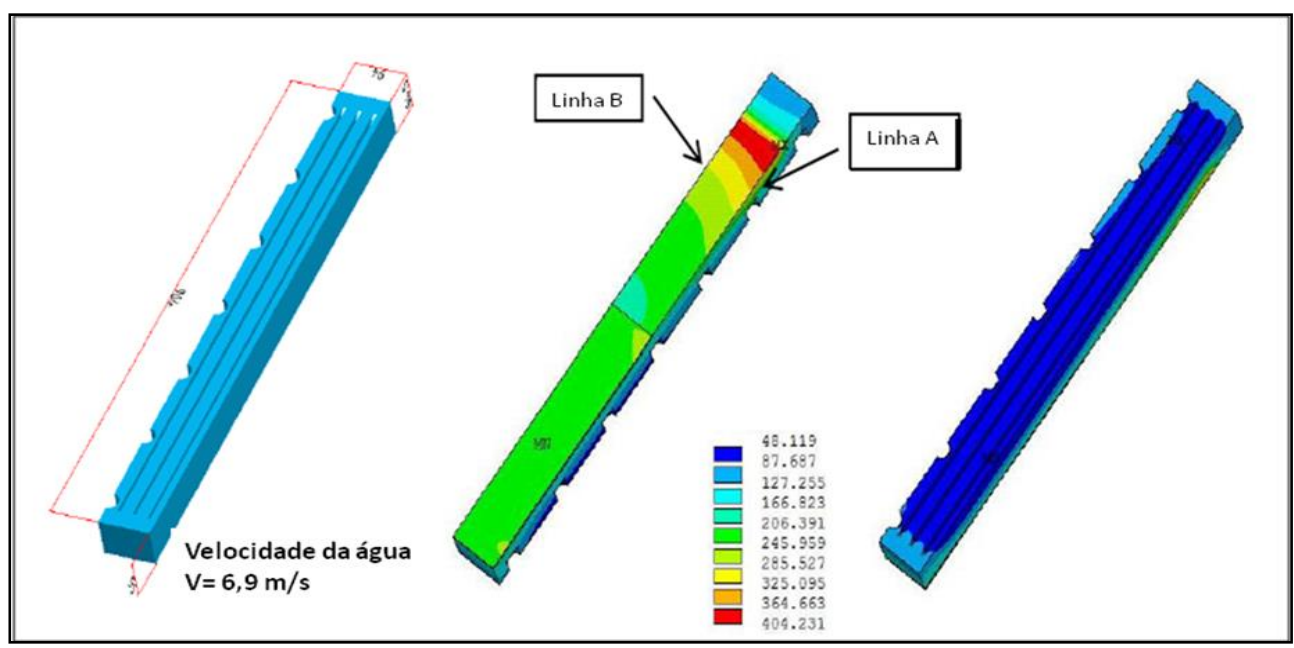

Figura 7. Análise em 3D do perfil de temperatura do revestimento step níquel.

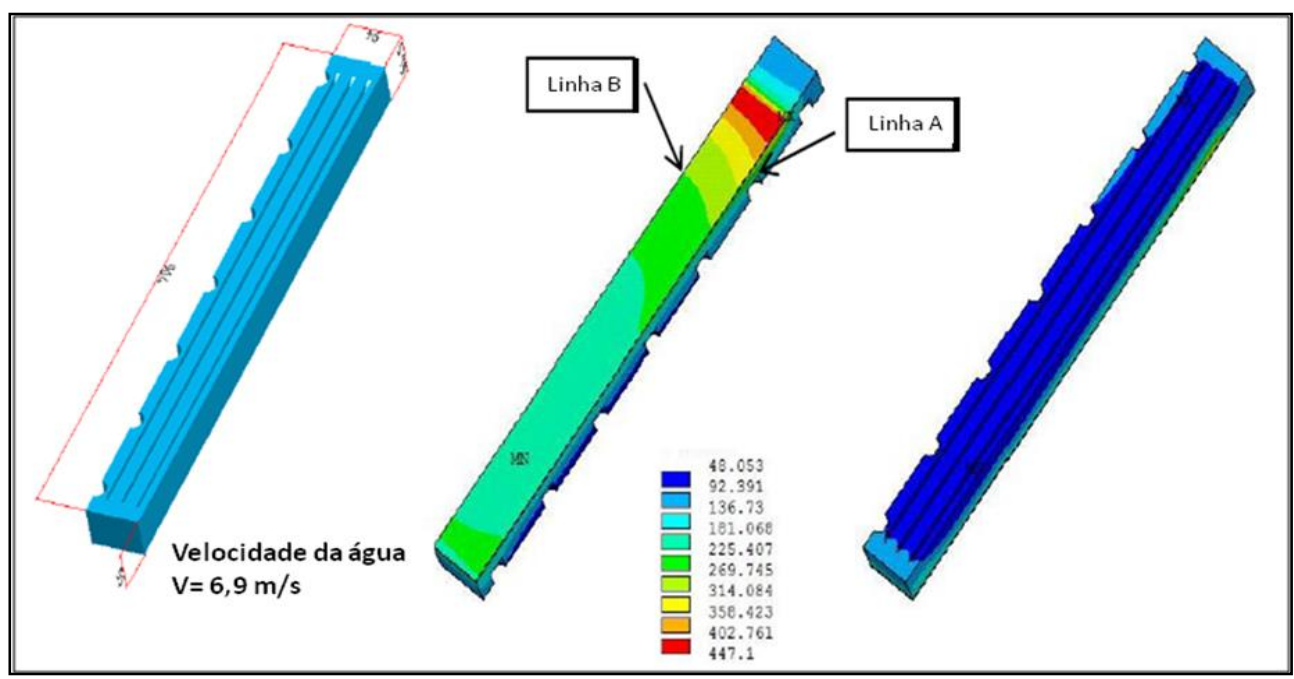

Figura 8. Análise em 3D do perfil de temperatura do revestimento UniGuard ${ }^{\mathrm{TM}}$ "full face".

Durante testes com revestimento UniGuard ${ }^{\mathrm{TM}}$ em um determinado cliente, foram realizados algumas medições para avaliação do fluxo de calor do molde e verificar a 
influência do revestimento UniGuard ${ }^{\mathrm{TM}}$ no sistema. Para o cálculo do fluxo utilizou-se os parâmetros de processo como nível do molde, dimensões das placas lingotadas, $\Delta$ temperatura (temperatura de saída - temperatura de entrada) em uma velocidade de lingotamento constante. Conforme observado na Figura 13, a extração de calor no molde revestido com UniGuard ${ }^{\mathrm{TM}}$ não apresentou diferença significativa em comparação com o molde revestido com níquel e nenhum distúrbio no sistema de detecção de alarmes foi detectado.

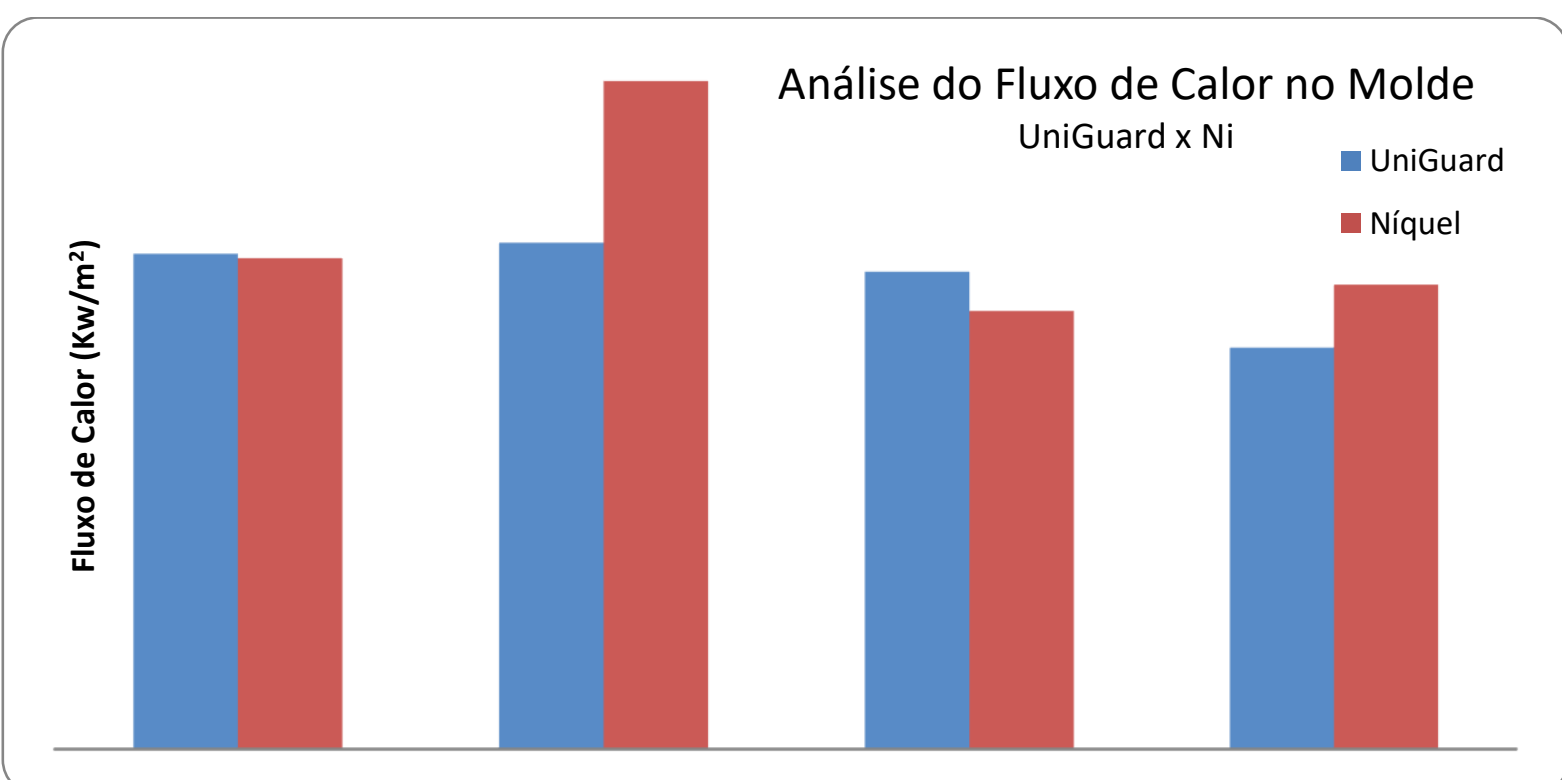

Figura 9. Análise de fluxo de calor no molde UniGuard ${ }^{\mathrm{TM}}$ versus Níquel".

O revestimento UniGuard ${ }^{\mathrm{TM}}$ está sendo testado nos principais lingotamentos contínuos do Brasil com resultados bastante satisfatórios. Os moldes se encontram em operação e a SMS Siemag tem desenvolvido juntamente com os clientes mecanismos para prolongar a vida do molde bem como entender o comportamento deste novo produto que ajudará as usinas na redução de custos.

\subsection{Recuperação de Mancais de linhas de laminação via processo Arc Spray}

Mancais são elementos de máquinas que servem de apoio fixo aos elementos de movimento giratório (eixos) são geralmente construídos de ferro fundido ou Aço. A maioria de maquinas e equipamentos mecânicos que necessitam de movimento de giro possuem mancais. A função principal dos mesmos é assegurar a movimentação rotativa entre duas superfícies com baixo nível de atrito suportando as cargas envolvidas no sistema.

Os Mancais são divididos em tipo deslizante e de rolamento. O Mancal deslizante é conhecido como mancal Hidrodinâmico, onde uma camada de fluido fica entre o mancal e o eixo, reduzindo desta forma o atrito entre partes. Pequenos canais permitem a passagem do lubrificante. O Mancal de rolamento tem este nome pela característica da instalação de um rolamento entre o mancal e o eixo que por sua vez tem a função de suportar cargas do mecanismo e reduzir o atrito.

A SMS Group vem desenvolvendo pesquisas e aplicando processos inovadores para recuperação de todos os tipos de Mancais presentes na Siderurgia. 
Adquirindo o Know-How dos nossos colegas da SMS Milcraft - USA, nós da SMS Brasil, desenvolvemos e estamos aplicando os processos de recuperação por Aspersão térmica via ARC Spray em Mancais de deslizamento.

$\mathrm{Na}$ metalização pelo processo ARC SPRAY (ou Arco Elétrico), dois arames consumíveis são energizados, e a diferença de potencial elétrico entre eles provoca a abertura de um arco elétrico, que desta forma funde o material. Posteriormente, um jato de ar comprimido de alta pressão projeta as partículas sobre a superfície, formando assim o revestimento.

As grandes vantagens do processo são as altas taxas de deposição de material que consequentemente promove uma recuperação em menor tempo, o baixo aporte térmico de calor que por sua vez não provoca distorções às peças, camada mais homogênea que o processo de soldagem garantindo desta forma uma redução de material a ser removido pelo processo de usinagem, operação simples, redução de custos e revestimentos de qualidade excepcional. Aplicam-se uma vasta gama de arames metálicos e suas ligas, além de arames tubulares especiais.

Se tratando de mancais de deslizamento, outra grande vantagem a ser levada em consideração é a caraterística micro porosa do revestimento aplicado via ARC SPRAY do qual permite que o fluido penetre por capilaridade entre os micro poros garantindo uma melhor lubrificação e redução de atrito entre partes.

Abaixo algumas figuras que representam o processo de recuperação realizado pela SMS em Mancais.

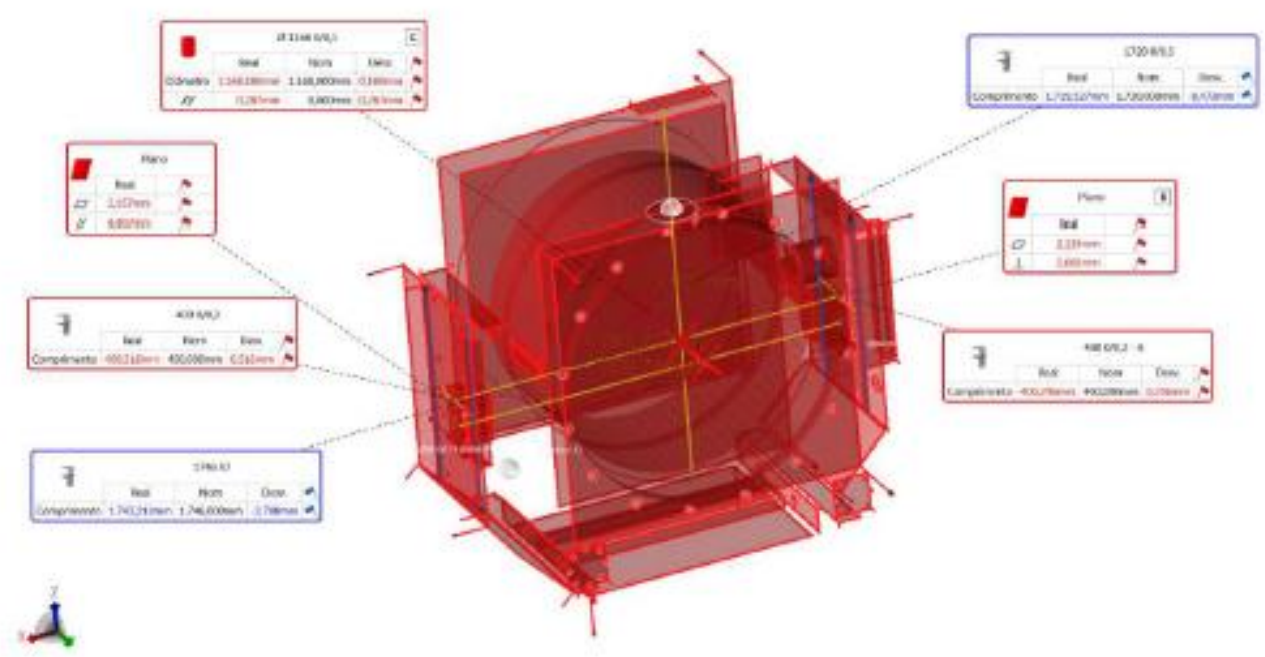

Figura 10. Controle dimensional realizado durante a peritagem de um mancal do Backup Roll 


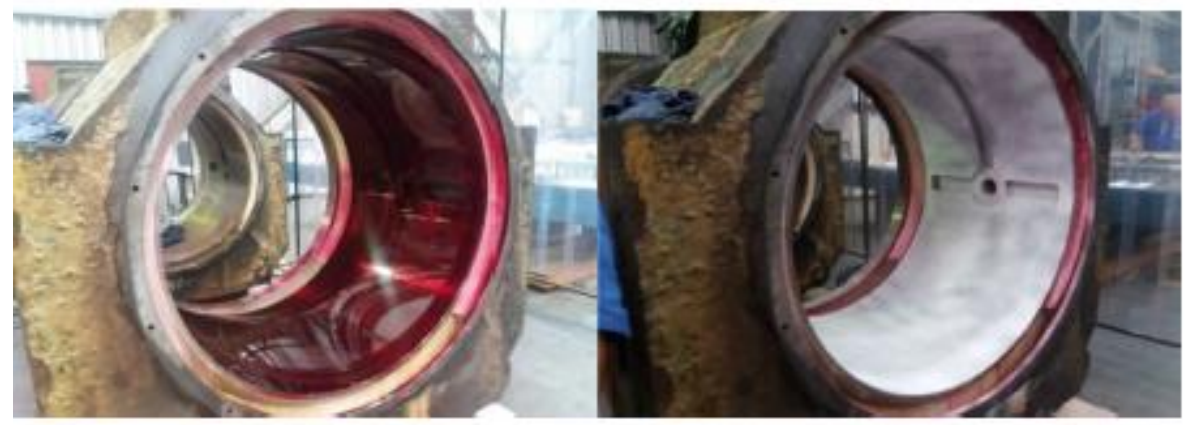

Figura 11. Inspeção por Líquido Penetrante no diâmetro interno de um mancal do Backup Roll

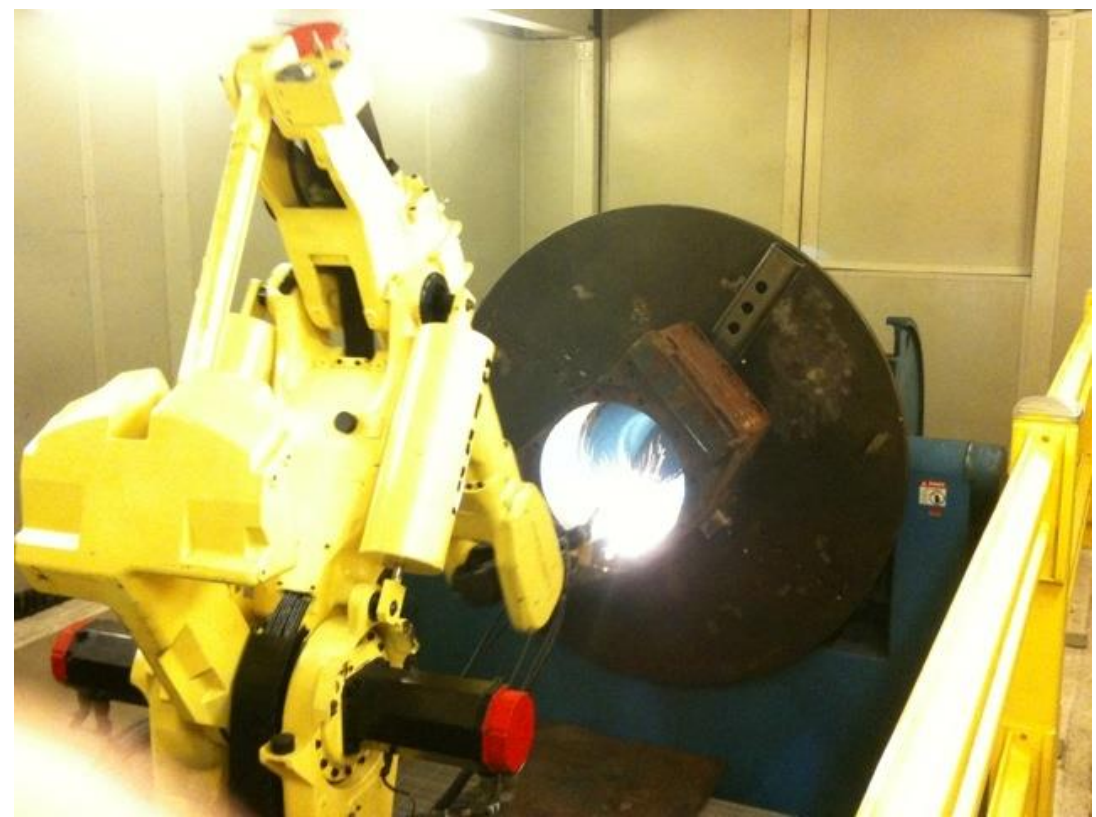

Figura 12. Revestimento via ARC Spray em Mancais de Linhas de Laminação

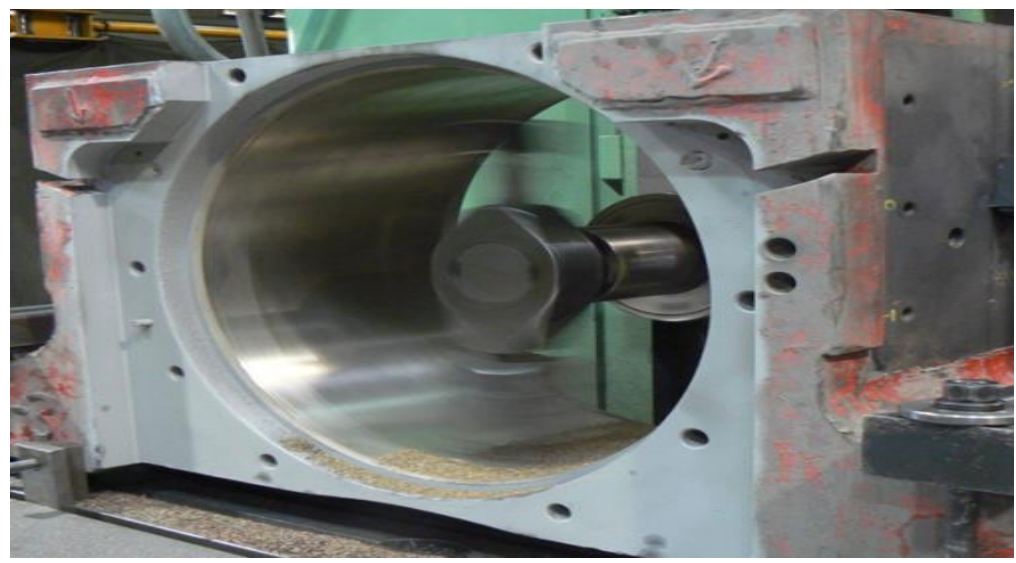

Figura 13. Usinagem após metalização em Mancais de Linhas de Laminação

A SMS recomenda realizar a recuperação através de Processo Arcspray tendo em vista o menor aporte térmico em relação a Processo de Soldagem, especialmente tratando-se de grande volume de deposição. Devido à dilatação e contração durante de aquecimento e resfriamento em uma recuperação por solda, há a possibilidade de distorção de roscas e perca de posição dos furos, impossibilitando a montagem. 
O Processo ArcSpray evita estes problemas e proporciona propriedades mecânicas necessária para esta aplicação.

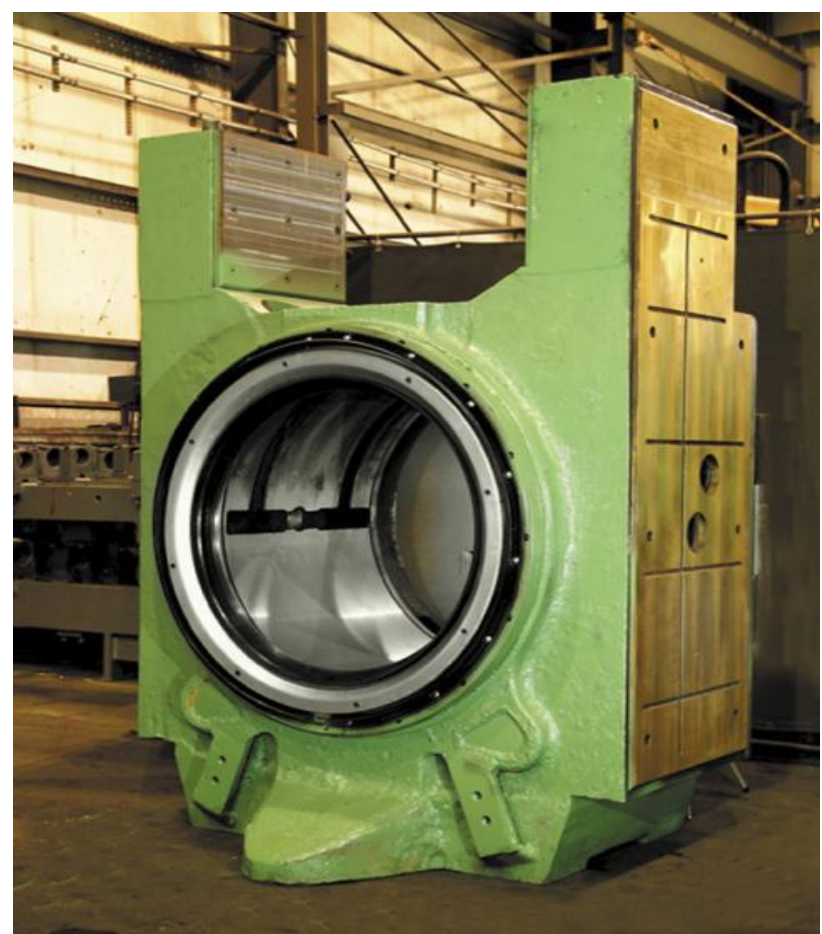

Figura 13. Referência Mancal Nucor Steel Tuscaloosa, Recuperado pela SMS Group

\subsection{Análise e Desenvolvimento de revestimentos aspergidos via HVOF em substituição ao cromo duro.}

Mediante a solicitação do cliente e visualização de melhoria, temos capacidade de desenvolver estudos e analisar as melhores viabilidades de negocio para aumento de performance de equipamentos mecânicos. A seguir apresentamos uma breve citação de como foi feita uma análise para substituição de processo e material para revestimento.

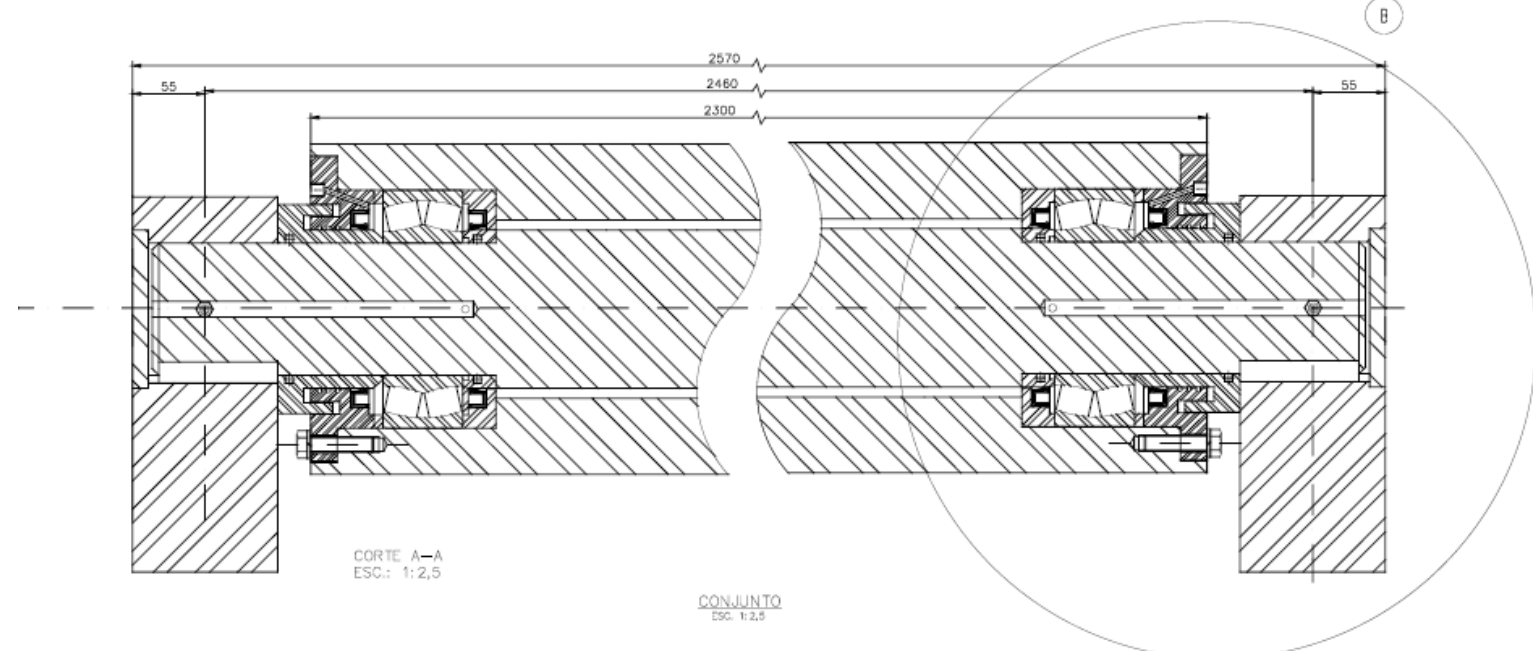

Figura 14. Passline Roll do Stretch Bending Unit 
Passline Roll são rolos que trabalham na área de decapagem no equipamento chamado Stretch Bending que tem por função desempenar as chapas da laminação a frio após a decapagem química, tais rolos, devido as características de funcionamento do equipamento, sofrem grandes tensões e desgaste por abrasão. A Concepção inicial do rolo é adota de um material aço liga e posterior revestimento de cromo duro na superfície da camisa. Em busca de uma melhor vida útil que o revestimento por cromo duro, foi solicitado uma análise de viabilidade de substituição de processo.

Estudos realizados [4] demonstram a viabilidade técnica da substituição de revestimentos de cromo duro por revestimentos depositados através de aspersão térmica via HVOF devido as excelentes propriedades mecânicas, resistência ao desgaste e corrosão, taxa de deposição elevada e acabamento superficial superior ao cromo duro. Geralmente, devido a importação de matéria prima, revestimentos via HVOF tem um custo direto mais elevado que o cromo duro, em contra partida ao custo direto do processo, a maior vida útil obtida (podendo chegar a ser $5 x$ superior ao cromo duro [5]) gera redução nas perdas por paradas para manutenção, redução de troca direta de peças, menor tempo para deposição e se alia ao fato de que não são gerados efluentes que necessitam de tratamento tal como o cromo duro.

As figuras 15 e 16 apresentam a micrografia obtida após analise por microscopia ótica dos dois elementos estudados Cromo Duro e Wc-CoCr.

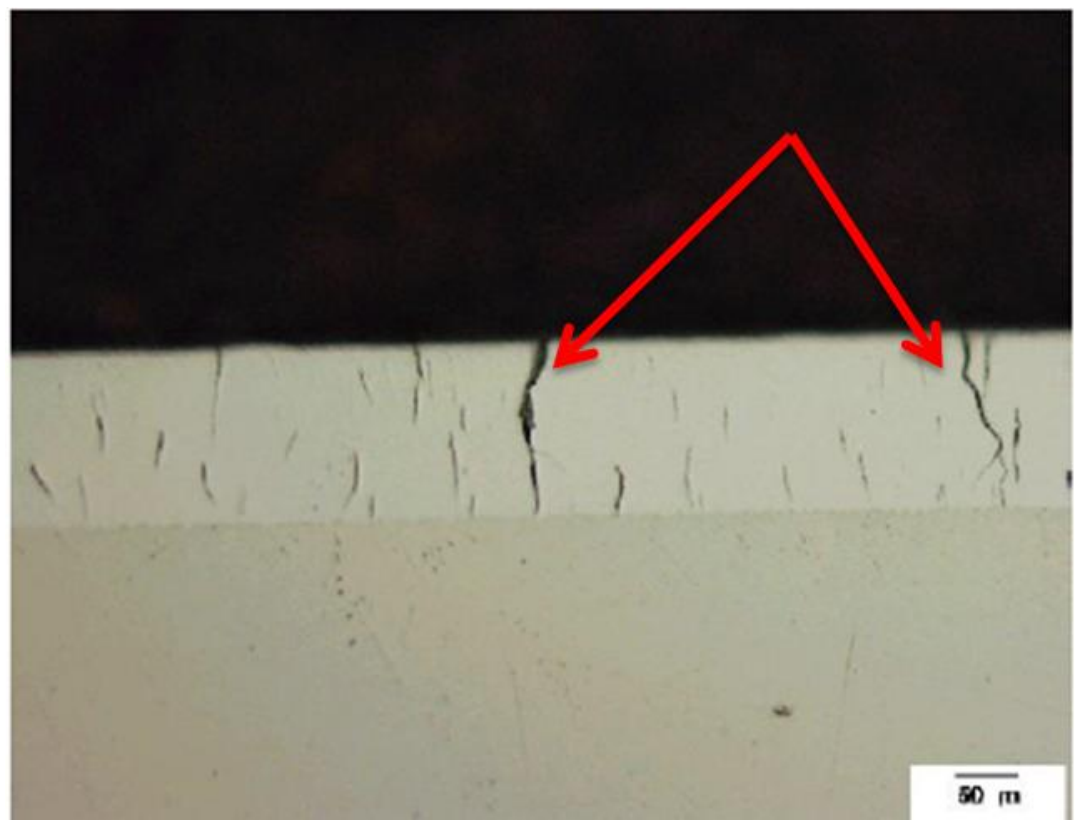

Figura 15. Seção Transversal - Revestimento de Cromo Duro (200x) 


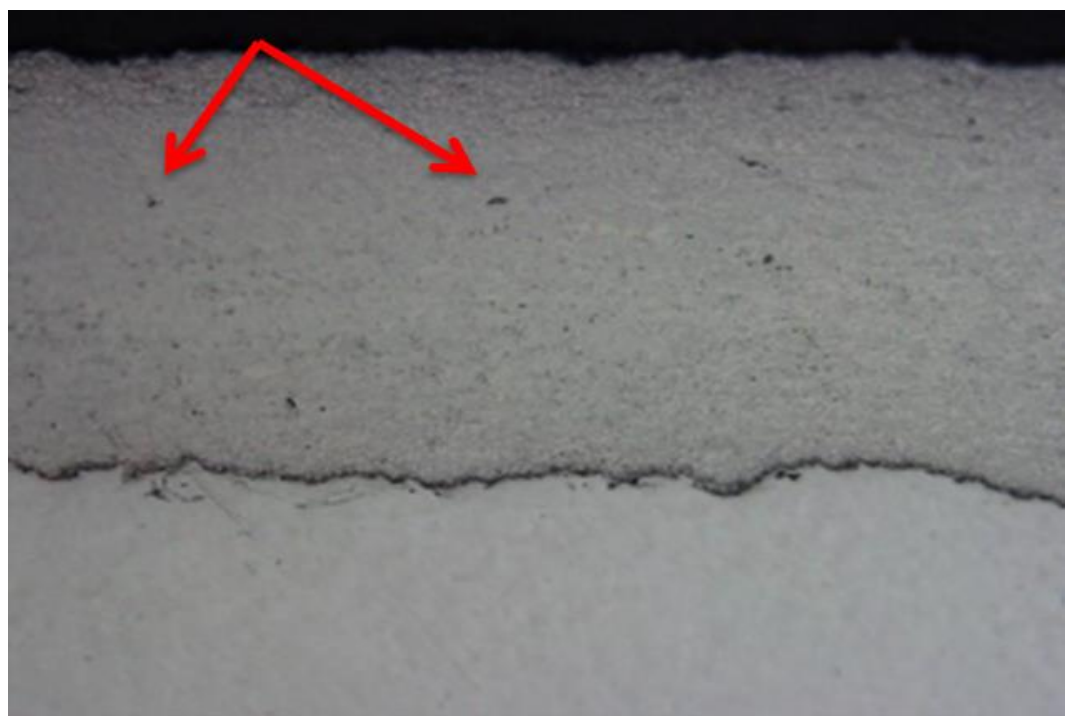

Figura 15. Seção Transversal - Revestimento via HVOF Wc-CoCr(200x)

$\mathrm{Na}$ figura 14, foi possível observar a microestrutura típica do cromo duro. Evidenciando porosidade fechada do revestimento, bem como algumas trincas verticais devido ao alivio das tensões residuais comuns do tipo de processo.

Em relação a microestrutura da figura 15 encontradas nos revestimentos de WcCoCr depositadas por HVOF, foi possível observar um revestimento com característica lamelar típica de revestimentos aspergidos, contendo discreta película de óxidos e porosidade média de $1 \%$.

Em base as microestruturas, pode-se observar que as trincas verticais do cromo duro são propicias para passagem de agentes de corrosão até o metal base, reduzindo desta a proteção do cromo duro contra este meio de desgaste.

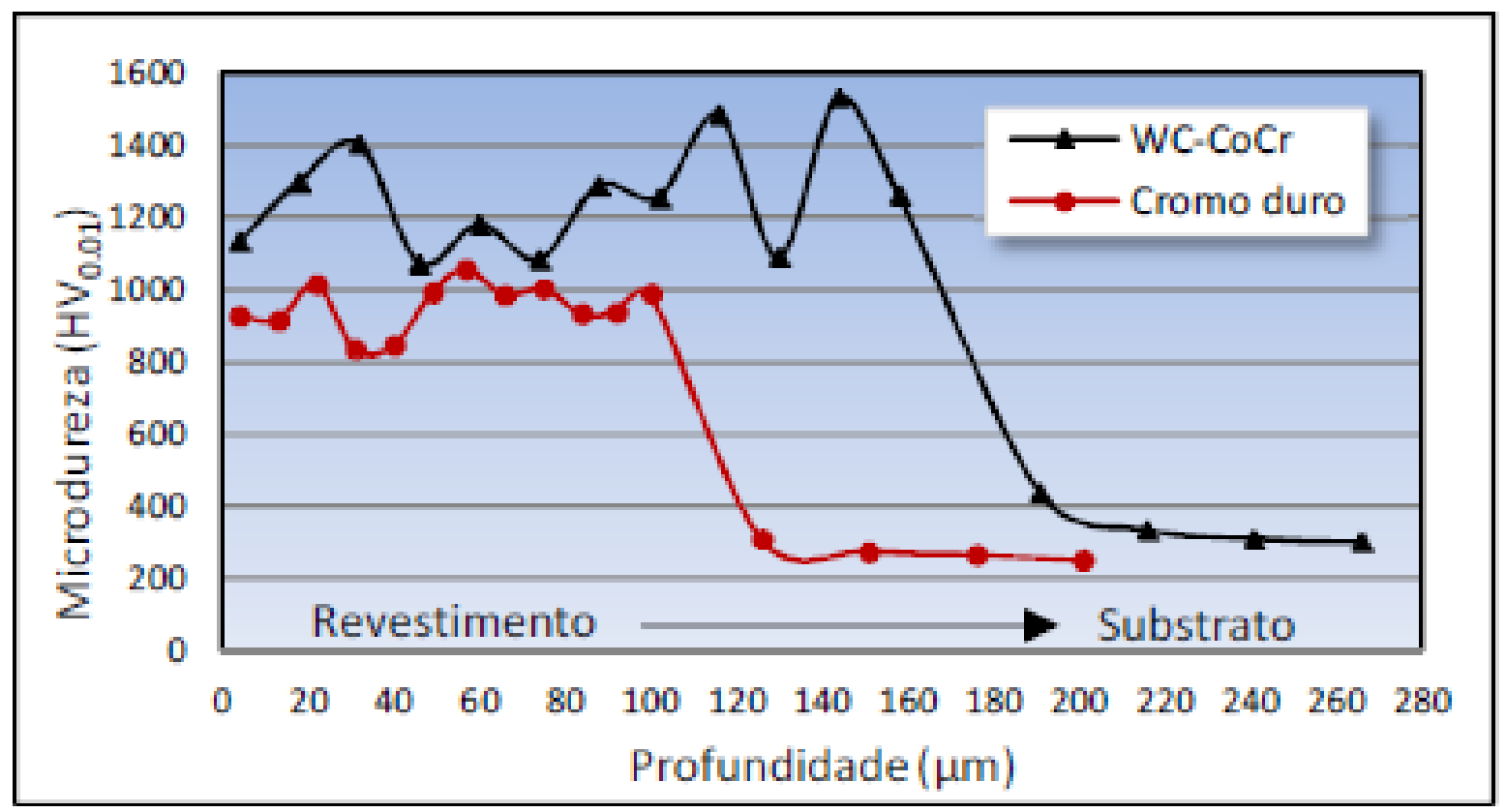

Figura 15. Valores da micro dureza ao longo da seção transversal do revestimento 
$\mathrm{Na}$ figura 15, observam-se os valores de micro dureza encontrados ao lonfo da seção transversal do revestimento. Nota-se uma dureza mais elevada no revestimento feito por aspersão térmica utilizando $\mathrm{Wc}-\mathrm{CoCr}$

Na figura 5, é apresentado o corpo de prova de cada revestimento com marcas características do tipo de ensaio do qual foram submetidos.
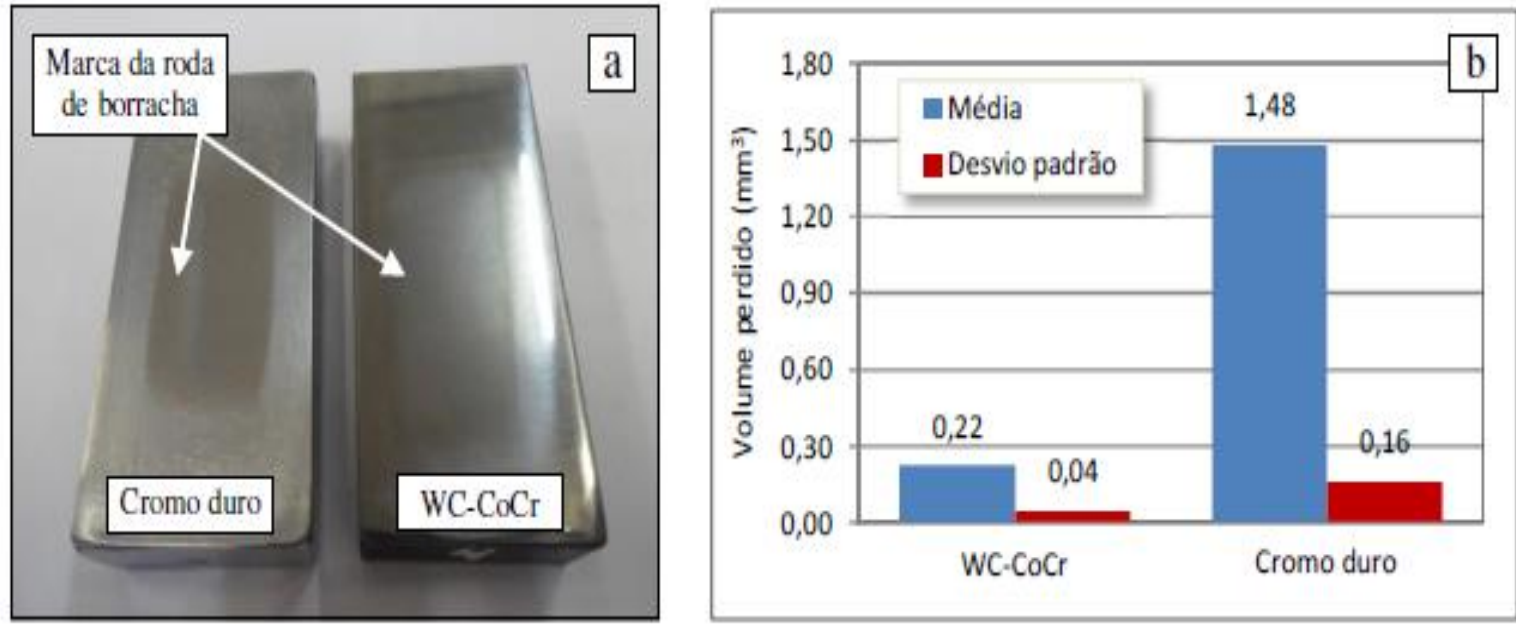

Figura 16. Resultados do ensaio de desgaste conforme norma ASTM G65-00. (a) marcas características do ensaio e (b) média de perda de volume

Nota-se que o corpo de prova revestido por cromo duro apresenta uma condição visual de desgaste abrasivo mais acentuada em relação ao revestimento de Wc$\mathrm{CoCr}$ depositado por HVOF. A figura $16 \mathrm{~b}$ representa uma comparativa entre os volumes perdidos de ambos. Verifica-se que o revestimento WC-CoCr apresentou um desempenho muito superior comparado ao cromo duro, resultando numa perda de volume de $0,22 \mathrm{~mm}^{3}$ contra $1,48 \mathrm{~mm}^{3}$

\section{CONCLUSÃO}

Embora ainda não estejam muito difundidos no Brasil, os revestimentos por aspersão térmica possuem inúmeras aplicações e garantem uma proteção contra mecanismos de desgaste superior a outros tipos de revestimentos, especialmente quando se trata de Carbetos aplicados por HVOF.

Observa-se também a aplicação da aspersão térmica pelo processo de ARC SPRAY para recuperação de mancais do qual tem um aporte térmico reduzido em relação ao processo de soldagem, garantindo assim que não ocorra dilatação e contração durante o processo de recuperação, desta forma, evitando distorções geométricas que resultem em deslocamento de posição dos furos.

Os resultados apresentados na análise 3.4 confirmam que o revestimento $\mathrm{WC}$-CoCr, aspergido por HVOF é uma alternativa confiável comparado com o cromo duro eletrolítico, garantindo uma estrutura mais densa, com porosidade média de $1 \%$ e com uma resistência ao desgaste muito superior. 


\section{Agradecimentos}

À SMS Group pela oportunidade de desenvolvimento técnico em todas as áreas da Siderurgia e no contexto deste trabalho pelos estudos, treinamentos e aplicações de revestimentos por Aspersão Térmica.

\section{REFERÊNCIAS}

1 AWS. Thermal Spraying - Practice, Theory and Application.

2 PAWLOWSKI, L. The Science and Engineering of thermal Spray Coatings. Ed. John Willey \& Sons, $2^{a}$ ed. England, 2008. 647p.

3 O. COUTO, L. C. Metalização/Aspersão térmica - Enfâse Metalização Hipersônica (HP-HVOF/HVOF). Apostila de Treinamento. Vespasiano, Maio 2016. 62p.

4 STARWELL, B.; LEGG, K.; Hard Chrome Alternatives Team - Tri Serice Validation of HVOF Thermal Spray as a Chrome Replacement for Aircraft. Rowan Technology Group, 2001.

5 MYIOSHI, K. Solid Lubrification Fundamentals and Applications - Properties of Clean Surfaces: Adhesion, Friction and Wear. Cleveland: National Aeronautics and Space Administration - Lewis Research Center, 1998. 52p 